\title{
Studies on Chitin. VI. Preparation and Properties of Alkyl-Chitin Fibers
}

\author{
Seiichi ToKura, Jun YoshidA, Norio NisHI, \\ and Toshifumi HIRAOKI \\ Department of Polymer Science, Faculty of Science, Hokkaido University, \\ Nishi 8-chome, Kita 10-jo, Kita-ku, Sapporo 060, Japan.
}

(Received January 22, 1982)

\begin{abstract}
Alkali-chitin was prepared by a simple procedure which included a freezing process in a sodium hydroxide-sodium dodecylsulfate system. Its alkylations were achieved with various alkyl halides of different chain lengths and bulkiness. The affinity toward water or formic acid was remarkably enhanced by the alkylations in spite of the low degree of substitution. The increase in hydrophilicity was considered to be result from the partial destruction of crystalline structure in the chitin molecule. The alkyl-chitin fibers were successfully prepared by spinning the solution of alkyl-chitin in formic acid-dichloroacetic acid mixture into ethyl acetate. The extent of swelling with water was found to correspond both to the chain length and the bulkiness of the alkyl group. The hydroxyl group at the $\mathrm{C}_{6}$ position is considered to be substituted prior to that of $\mathrm{C}_{3}$ position, according to a ${ }^{13} \mathrm{C}$ NMR study. ${ }^{1} \mathrm{H}$ NMR and elemental analysis proved useful in estimting the degree of alkylation even in the case of low degree of substitution.

KEY WORDS Chitin / Alkyl-Chitin / Freezing Process / Alkylation / Alkyl-

Chitin Fiber / ${ }^{1} \mathrm{H}$ NMR / ${ }^{13} \mathrm{C}$ NMR / Elemental Analysis /
\end{abstract}

Chitin, a natural abundant polysaccharide, is known to be sparingly soluble in general organic solvents owing to its strong crystalline structure through hydrogen bonds. Successful regeneration of chitin as a fiber or film was carried out by methods in which chitin was dissolved in formic acid directly. ${ }^{1}$ The preparation of acetyl-chitins and their fibers was also carried out successfully. ${ }^{2,3}$ The acylation reactions of chitin with longer or more bulky groups were found to improve its solubility properties in organic solvents. ${ }^{4,5}$

In the present study, the partial destruction of the crystalline structure in chitin molecule was carried out so as to increase its affinity toward water by alkylation, using various groups of different chain lengths and bulkiness. The enhancement of affinity toward water or other solvents enables chitin to take on a greater number of uses. The bulkiness and chain length of the attached alkyl-groups were found to be major factors in increasing the hydrophilicity of chitin derivatives even in the case of low degree of substitution. The degree of alkylation estimated by ${ }^{13} \mathrm{C}$ or ${ }^{1} \mathrm{H}$ NMR was roughly com- parable with that by elemental analysis. The initial alkylation site on the $N$-acetylglucosamine residue was suggested from ${ }^{13} \mathrm{C}$ NMR study to be the hydroxyl group at $\mathrm{C}_{6}$ position.

\section{EXPERIMENTAL}

\section{Chitin}

Chitin, prepared from Queen Crab shell, was kindly supplied from Kyowa Yushi Co. Ltd. and it was powdered to a $45-60$ mesh before use.

\section{Reagents}

Alkyl halides (methyl iodide, ethyl bromide, $n$ butyl bromide, $i$-butyl bromide, $t$-butyl bromide, $n$ amyl bromide, $i$-amyl bromide, and $t$-amyl bromide) were purchased from Wako Pure Chemical Industries Ltd. and used without further purification.

\section{Alkali-Chitin}

$10 \mathrm{~g}$ of chitin powder was added to $40 \mathrm{ml}$ of a $40 \%$ sodium hydroxide solution containing $0.2 \%$ sodium 
dodecylsulfate (SDS) at $4^{\circ} \mathrm{C}$ and the mixture was made to stand for $1 \mathrm{~h}$ at $4^{\circ} \mathrm{C}$ until the chitin became swollen. The chitin sulurry was kept at $-20^{\circ} \mathrm{C}$ overnight.

\section{Alkylation of Chitin}

The frozen alkali-chitin was suspended directly in alkyl halides ( 10 equivalent moles of alkyl halide for one $N$-acetylglucosamine residue) and the reaction was carried out at $12-14^{\circ} \mathrm{C}$ for $24 \mathrm{~h}$ with occasional mechanical stirring. The reaction mixture was neutralized with diluted acetic acid and the precipitate was collected by filtration. The product was dried in air after successive washing with ethanol, water, ethanol, and finally with acetone.

\section{Estimation for the Degree of Alkylation}

The degree of alkylation was estimated primarily from elemental analysis using a Yanagimoto $\mathrm{CHN}$ Corder MT-2, going on the assumption that a half mole of water was included per each $\mathrm{N}$-acetylglucosamine residue. ${ }^{2}$ As there was fairly good agreement between the theoretical and analytical values of elemental analysis as shown in Table I, chitin was not considered to be deacetylated during the preparation. An ${ }^{1} \mathrm{H}$ NMR measurement was also made for estimating the degree of alkylation, using a JEOL FX-400 (400 MHz) spectrometer in deuterated formic acid (DCOOD) at a polymer concentration of $1.8 \%$ and $45^{\circ} \mathrm{C}$. The chemical shift was measured relative to that of HDO. ${ }^{13} \mathrm{C}$ NMR measurements were made with a JEOL FX-60Q $(15 \mathrm{MHz})$ to estimate the initial alkylation site on the $N$-acetylglucosamine residue using 1.2 ethylated chitin in DCOOD at $45^{\circ} \mathrm{C}$. The chemical shift was measured relative to the center peak of DCOOD. The degree of alkylation at $\mathrm{C}_{6}$ position was calculated by a comparison of the peak areas between the alkylated and unreacted sites using the gated decoupling method. 1.2 ethylated chitin was prepared only for NMR analysis by reacting alkali-chitin with diethyl sulfate at $12-14^{\circ} \mathrm{C}$ for $24 \mathrm{~h}$.

\section{Preparation of Alkyl-Chitin Fibers}

The fibers of alkyl-chitins were prepared by spinning the solution of alkyl-chitin in formic aciddichloroacetic acid mixture into ethyl acetate, as was done in the preparation of chitin ${ }^{1}$ or acetylchitin fibers ${ }^{3}$ except there was no stretching bath. In contrast to the treatment of chitin fibers, the alkyl- chitin fibers were stretched in air immediately after the coagulation, since they quickly swell with water and become fragile. The stretched fibers were immersed in ethanol containing $\mathrm{NaOH}$ so as to remove any dichloroacetic or formic acid. The fibers were washed with ethanol successively and then dried in air.

\section{Properties of Alkyl-chitin Fibers}

The tensile strength, elongation and Young's modulus of alkyl-chitin fibers were measured by the method reported previously. ${ }^{1}$

\section{Degree of Swelling of Fiber}

The degree of swelling of alkyl-chitin fiber was estimated both by the microscopic observation and the titration of water with automatic Kirl-Fischer titration apparatus of Hirama Aquacounter AQ-3. In the microscopic observation, pictures were taken before and after contact with water, and the diameter of the dry and swollen fibers was measured from the pictures. In order to estimate the amount of absorbed water, fiber bandles were immersed in water at $25^{\circ} \mathrm{C}$ for $3 \mathrm{~min}$, and the swollen fibers were subjected to an Aquacounter at $20^{\circ} \mathrm{C}$ following the removal of water from the surface of fibers with filter paper.

\section{Heat Transition of Alkyl-Chitin}

The energies of heat transition at $151-226^{\circ} \mathrm{C}$ were measured by differential scanning calorimetric analysis using differential scanning calorimeter Rigaku $8001-\mathrm{SL} / \mathrm{C}$ by applying a $45-60$ mesh of alkyl-chitin powder against aluminum oxide. The energies of heat transition were estimated by making reference to that of freshly prepared urea $\left(\mathrm{mp} 130^{\circ} \mathrm{C}\right)$ at a heating rate of $5^{\circ} \mathrm{C} / \mathrm{min}$ in sealed aluminum cell.

\section{RESULTS AND DISCUSSION}

\section{Preparation of Alkali-Chitin}

Sodium dodecylsulfate (SDS) and the freezing process were necessary for the preparation of watersoluble alkali-chitin with $40 \%$ sodium hydroxide solution. Alkali-chitin prepared without SDS or freezing process never disperses well in ice water. The penetration of the sodium hydroxide solution into the crystalline structure of chitin is probably promoted by a detergent such as SDS, and the 
freezing process is considered to work for the destruction of the crystalline structure.

The deacetylation from chitin molecule is not considered to occur during the preparation of alkali-chitin, since all procedures were carried out below $5^{\circ} \mathrm{C}$. This was confirmed by Noguchi et al. ${ }^{6}$ The extent of deacetylation from chitin molecule was also assumed to be less than $5 \%$, according to potentiometric titration of water-soluble carboxymethyl-chitin, even under more drastic conditions. ${ }^{7}$

Although the Hakomori method ${ }^{8}$ also was found effective in preparing alkali-chitin, the procedures involved were somewhat more complicated.

Table I. Elemental analyses of chitin and alkyl-chitins

\begin{tabular}{|c|c|c|c|c|c|}
\hline \multirow{2}{*}{ Samples } & & $\mathrm{C}$ & $\begin{array}{r}\mathrm{H} \\
\end{array}$ & $\begin{array}{r}\mathrm{N} \\
\end{array}$ & \multirow{2}{*}{ D.S. ${ }^{\mathrm{a}}$} \\
\hline & & $\%$ & $\%$ & $\%$ & \\
\hline \multirow{2}{*}{ Chitin } & Calcd & 45.28 & 6.60 & 6.60 & \multirow[t]{2}{*}{$0^{\mathbf{b}}$} \\
\hline & Found & 44.96 & 6.50 & 6.57 & \\
\hline \multirow{2}{*}{ Ethyl-chitin } & Calcd & 47.31 & 6.54 & 6.27 & \multirow[t]{2}{*}{$0.4^{\mathrm{c}}$} \\
\hline & Found & 47.11 & 6.70 & 6.40 & \\
\hline \multirow{2}{*}{ Ethyl-chitin } & Calcd & 51.06 & 7.63 & 5.74 & \multirow[t]{2}{*}{$1.2^{\mathrm{d}}$} \\
\hline & Found & 50.96 & 7.36 & 6.17 & \\
\hline \multirow[t]{2}{*}{$n$-Butyl-chitin } & Calcd & 49.14 & 7.33 & 6.02 & \multirow[t]{4}{*}{$0.4^{\mathrm{e}}$} \\
\hline & Found & 48.55 & 6.87 & 6.32 & \\
\hline$i$-Butyl-chitin & Found & 48.88 & 6.71 & 6.38 & \\
\hline$t$-Butyl-chitin & Found & 48.75 & 6.87 & 6.40 & \\
\hline \multirow[t]{2}{*}{ n-Amyl-chitin } & Calcd & 50.00 & 7.08 & 5.83 & \multirow[t]{4}{*}{$0.4^{\mathrm{f}}$} \\
\hline & Found & 49.01 & 7.18 & 6.08 & \\
\hline$i$-Amyl-chitin & Found & 49.33 & 7.39 & 6.00 & \\
\hline t-Amyl-chitin & Found & 49.26 & 7.41 & 6.05 & \\
\hline
\end{tabular}

a D.S., degree of substitution per $\mathrm{N}$-acetylglucosamine residue.

b Chitin. Calcd. for $\mathrm{C}_{8} \mathrm{H}_{13} \mathrm{NO}_{5} \cdot 1 / 2 \mathrm{H}_{2} \mathrm{O}$.

c Ethyl-chitin. Calcd for $\left(\mathrm{C}_{8} \mathrm{H}_{13} \mathrm{NO}_{5} \cdot 1 / 2 \mathrm{H}_{2} \mathrm{O}\right)_{0.6}+$ $\left(\mathrm{C}_{10} \mathrm{H}_{17} \mathrm{NO}_{5} \cdot 1 / 2 \mathrm{H}_{2} \mathrm{O}\right)_{0.4}=\mathrm{C}_{8.8} \mathrm{H}_{14.6} \mathrm{NO}_{5} \cdot 1 / 2 \mathrm{H}_{2} \mathrm{O}$.

d Ethyl-chitin of 1.2 substituted was prepared from alkali-chitin and diethyl sulfate in $i$-propyl alcohol. Calcd for

$$
\begin{gathered}
\left(\mathrm{C}_{10} \mathrm{H}_{17} \mathrm{NO}_{5} \cdot 1 / 2 \mathrm{H}_{2} \mathrm{O}\right)_{0.8}+\left(\mathrm{C}_{12} \mathrm{H}_{21} \mathrm{NO}_{5}\right)_{0.2}= \\
\mathrm{C}_{10.4} \mathrm{H}_{18.6} \mathrm{NO}_{5.4} .
\end{gathered}
$$

e Butyl-chitin. Calcd for $\mathrm{C}_{9.6} \mathrm{H}_{16.2} \mathrm{NO}_{5} \cdot 1 / 2 \mathrm{H}_{2} \mathrm{O}$.

f Amyl-chitin. Calcd for $\mathrm{C}_{10} \mathrm{H}_{17} \mathrm{NO}_{5} \cdot 1 / 2 \mathrm{H}_{2} \mathrm{O}$.

\section{Alkylation of Chitin}

Since the alkylation reaction was performed at low temperature to avoid deacetylation, the degree of alkylation per $N$-acetylglucosamine residue was not sufficient (around 0.4), independently of the molecular shape of the alkylation reagents, as shown by the results of elemental analyses in Table I. The low degree of substitution was probably due to the low reaction temperature and also the alignment of $\mathrm{N}$-acetylglucosamine residue in the crystalline structure of chitin as suggested by Pearson et al. ${ }^{9}$

Differential scanning calorimetric measurements were made to estimate the extent of destruction of crystalline structure on the alkyaltion reaction. A slight depression in the energy of heat transition around $220^{\circ} \mathrm{C}$ was observed for the vacuum dried samples on increasing the bulkiness of butyl groups as shown in Figure 1. But large enhancement of heat transition energy was observed with an increase in the bulkiness of the alkyl group when the butyl chitin powder were equilibrated with moisture at $40^{\circ} \mathrm{C}$. However, there was little difference in the

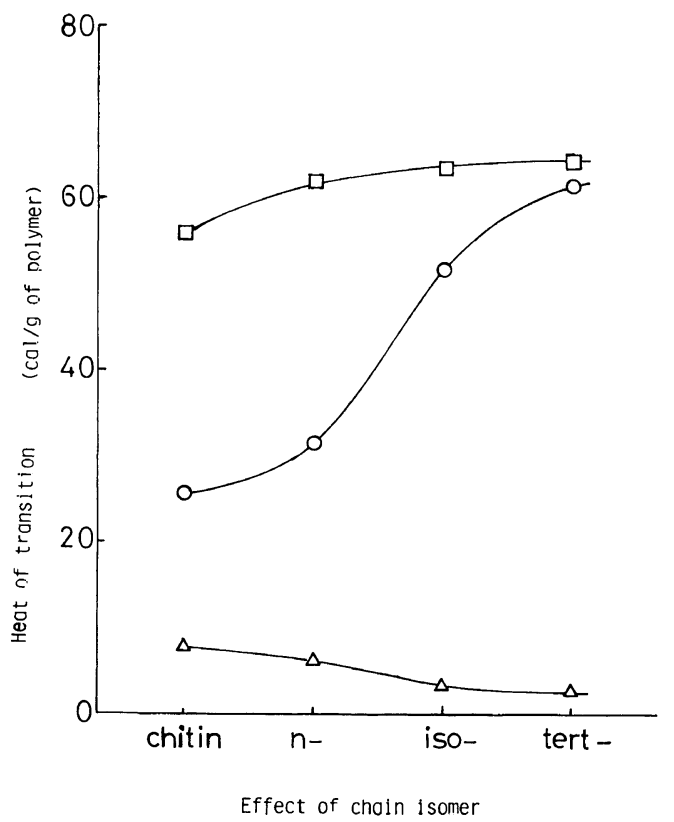

Figure 1. Heat transition of butyl-chitin powder: $-\triangle-$, dried in vacuo at $40^{\circ} \mathrm{C} ;-\mathrm{O}-$, equilibrated with moisture at $25^{\circ} \mathrm{C} ;-\square-$, soaked with water of $25^{\circ} \mathrm{C}$ for $3 \mathrm{~min}$. Energy of heat transition was estimated by reference to that of urea at heating rate of $5^{\circ} \mathrm{C} \mathrm{min}^{-1}$ 


\section{S. TOKURA et al.}

Table II. Properties of chitin and alkyl-chitin fibers

\begin{tabular}{|c|c|c|c|c|c|c|c|c|c|c|}
\hline \multirow{3}{*}{ Sample } & \multirow{3}{*}{$\frac{\text { Denier }}{\mathrm{d}}$} & \multirow{2}{*}{\multicolumn{2}{|c|}{$\frac{\text { Tenacity }}{\mathrm{gd}^{-1}}$}} & \multirow{2}{*}{\multicolumn{2}{|c|}{$\frac{\text { Elongation }}{\%}$}} & \multirow{3}{*}{$\frac{\begin{array}{c}\text { Knot } \\
\text { strength }\end{array}}{\mathrm{g} \mathrm{d}^{-1}}$} & \multirow{2}{*}{\multicolumn{2}{|c|}{$\frac{\text { Young's modulus }}{\mathrm{g} \mathrm{d}^{-1}}$}} & \multirow{3}{*}{$\frac{\text { Density }}{\mathrm{g} \mathrm{ml}^{-1}}$} & \multirow{3}{*}{ D. Sub. } \\
\hline & & & & & & & & & & \\
\hline & & Dry $^{a}$ & Wet $^{\mathrm{b}}$ & Dry & Wet & & Dry & Wet & & \\
\hline Chitin & 8.54 & 1.28 & 0.23 & 8.4 & 15.6 & 0.15 & 74.54 & 3.96 & 1.40 & 0 \\
\hline Chitin & 4.16 & 1.39 & 0.33 & 3.6 & 10.1 & 0.64 & 88.42 & 19.42 & 1.40 & 0 \\
\hline Methyl- & 3.73 & 0.60 & 0.06 & 4.2 & 3.5 & 0.20 & 45.80 & - & 1.37 & 0.4 \\
\hline Ethyl- & 2.99 & 1.25 & 0.33 & 3.5 & 13.2 & 0.32 & 86.12 & 3.40 & 1.39 & 0.4 \\
\hline$n$-But- & 4.15 & 0.79 & 0.10 & 1.0 & 7.1 & 0.11 & 108.26 & - & 1.43 & 0.4 \\
\hline$i$-But- & 5.58 & 1.42 & - & 4.6 & - & 0.12 & 92.72 & - & 1.44 & 0.4 \\
\hline$t$-But- & 3.56 & 0.92 & - & 3.5 & - & 0.15 & 86.52 & - & 1.41 & 0.4 \\
\hline n-Amyl- & 4.23 & 0.92 & - & 3.5 & - & 0.38 & 88.70 & - & 1.46 & 0.4 \\
\hline$i$-Amyl- & 3.69 & 1.20 & - & 3.5 & - & 0.13 & 102.79 & - & 1.41 & 0.4 \\
\hline$t$-Amyl- & 2.53 & 0.82 & 0.09 & 2.5 & 17.3 & 0.48 & 89.57 & - & 1.42 & 0.4 \\
\hline
\end{tabular}

a Dry: $20^{\circ} \mathrm{C}, 65 \%$ R.H.

b Wet: $20^{\circ} \mathrm{C}, 100 \%$ R.H.

c D. Sub.: Degree of substitution estimated from elemental analysis.

Table III. Chitin and alkyl-chitin fiber spacings

\begin{tabular}{|c|c|c|}
\hline \multirow{2}{*}{ Samples } & \multirow{2}{*}{$\frac{\text { Spacings }}{\AA}$} & \\
\hline & & \\
\hline \multirow{4}{*}{ Chitin } & $3.44-3.59$ & $\mathrm{~m}, \mathrm{q}$ \\
\hline & $3.72-3.88$ & $\mathrm{~m}, \mathrm{q}$ \\
\hline & $4.59-4.98$ & $\mathrm{~m}, \mathrm{q}$ \\
\hline & $7.70-12.59$ & $\mathrm{~m}, \mathrm{q}$ \\
\hline \multirow{4}{*}{$n$-Butyl-chitin } & $3.53-3.72$ & $q$ \\
\hline & $4.67-4.91$ & $\mathrm{~m}$ \\
\hline & $4.74-5.12$ & $\mathrm{q}$ \\
\hline & $5.38-5.60$ & $\mathrm{q}$ \\
\hline \multirow{3}{*}{$i$-Butyl-chitin } & $3.53-3.65$ & $q$ \\
\hline & $4.67-4.96$ & $\mathrm{~m}$ \\
\hline & $4.74-5.00$ & $\mathrm{q}$ \\
\hline \multirow{4}{*}{$t$-Butyl-chitin } & $3.53-3.65$ & $\mathrm{q}$ \\
\hline & $4.62-5.38$ & $\mathrm{~m}$ \\
\hline & $4.73-5.03$ & $\mathrm{q}$ \\
\hline & $5.32-5.51$ & $\mathrm{q}$ \\
\hline
\end{tabular}

energy of heat transition among the alkyl-chitins on the wet state, though the transition temperature was depressed to around $151^{\circ} \mathrm{C}$ by the presence of water. Since the increase in heat transition energy depends on the presence of water molecules, the partial destruction of the crystalline structure of chitin seems to be induced by alkylation and it is possible
Table IV. Size of fiber unit cells calculated from X-ray diffraction patterns

\begin{tabular}{lccc}
\hline \multirow{2}{*}{ Fibers } & \multicolumn{3}{c}{ Axis } \\
\cline { 2 - 4 } & $\mathrm{a}(\AA)$ & $\mathrm{b}(\AA)$ & $\begin{array}{c}\mathrm{c}(\AA) \\
\text { Fiber repeat }\end{array}$ \\
\hline Chitin & 4.7 & 10.5 & 10.3 \\
$n$-Butyl-chitin & 4.8 & 10.6 & 10.7 \\
$i$-Butyl-chitin & 4.9 & 10.9 & 10.7 \\
$t$-Butyl-chitin & 5.0 & 11.0 & 10.9 \\
\hline
\end{tabular}

that the resulting amorphous part easily absorbs water. The enhancement of the solubility of alkylchitin toward formic acid also seems to suggest an increase in the amorphous part of the chitin.

\section{Regeneration of Alkyl-Chitin Fibers}

The alkyl-chitin fibers were prepared by the wet spinning of alkyl-chitin-formic acid solution into ethyl acetate according to the method for preparing acetyl-chitin fibers. ${ }^{3}$ The water bath could not be used for stretching the coagulated alkyl-chitin fibers, since they quickly become fragile on absorbing water. Hence, the stretching procedure was carried out in the air to obtain well oriented fibers.

The properties of the alkyl-chitin fibers are listed in Table II along with those of chitin fibers whose properties did not improve with alkylation. 


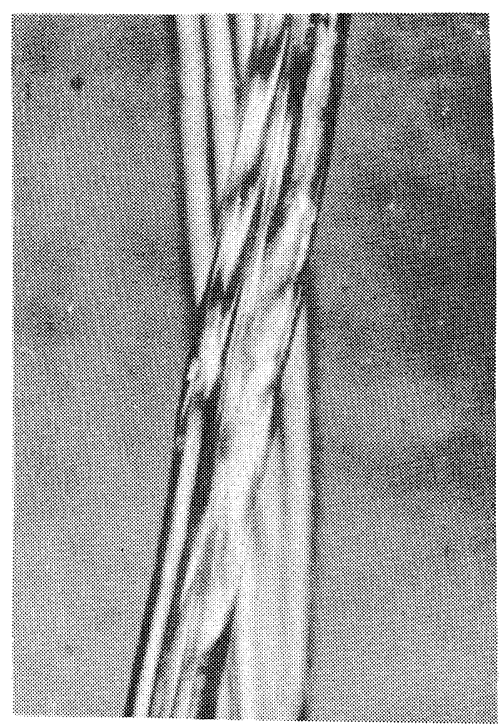

(Dry)

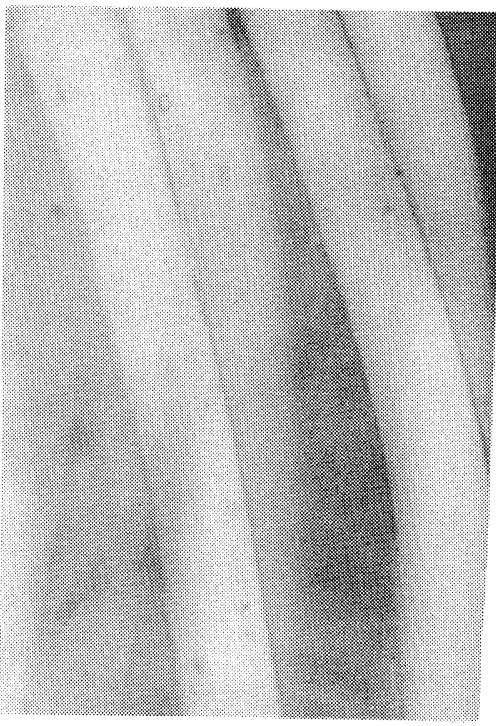

(Wet)

$15 \times 10$

Figure 2. Microscopic pictures of $n$-butyl-chitin fibers. Fiber pictures were taken before and after contact with water at $25^{\circ} \mathrm{C}$ for $3 \mathrm{~min}$. Diameters of dried or wet fibers were measured from these pictures.

However, the orientation of butyl-chitin fibers was generally better than that of chitin fibers from X-ray diffraction patterns whose spacings are listed in Table III along with those for chitin fibers. Although the amyl-chitin fibers showed a tendency similar to that of butyl-chitin fibers, the orientations of methyl- and ethyl-chitin fibers were nearly identical to that of the chitin fibers. ${ }^{1,10-13}$

The increase in the spacings of the regenerated alkyl-chitin fibers corresponds to a small extent to the bulkiness of attached alkyl group as shown in Table III. This might be possibly the result of steric hindrance of the butyl group on the reformation of rigid crystalline structure in the chitin molecule and thus the linear polysaccharide chain might slide easily to orient by stretching. The unit cells in the regenerated butyl-chitin fibers calculated from the values in Table III, seem to support above speculation in view of the slight expansion in the size of unit cell with increase in the bulkiness of the butyl group as shown in Table IV. The loose packing of molecules in the alkyl-chitin fibers did not change even after being subjected to such treatment as heating in vacuo or annealing.

The regenerated alkyl-chitin fibers quickly swell on contact with water as shown by the microscopic observations in Figure 2. The diameters of the dry

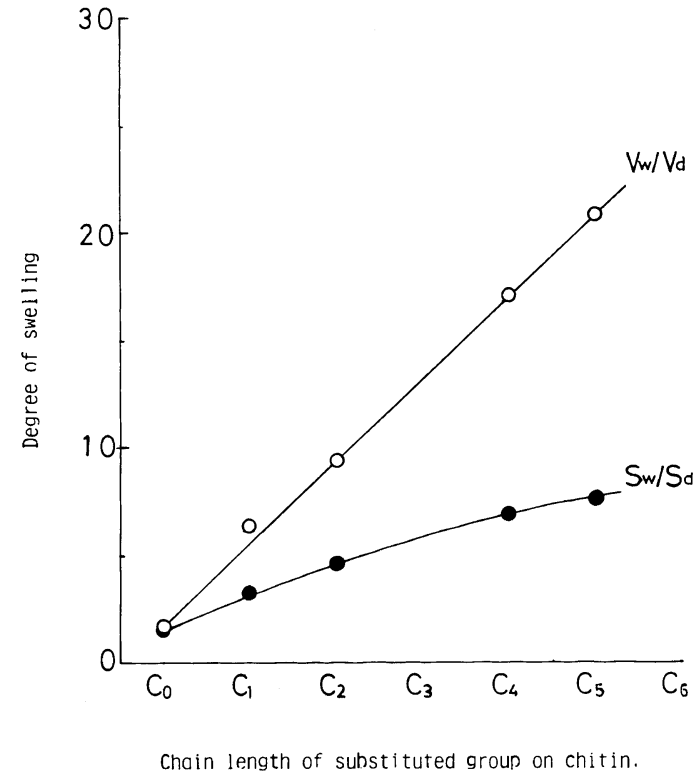

Figure 3. Dependence of the swelling on the chain length of linear alkyl groups. Degree of swelling is expressed as $V_{\mathrm{w}} / V_{\mathrm{d}}$ or $S_{\mathrm{w}} / S_{\mathrm{d}} . V$, volume of fiber; $S$, cross section of fiber.

and wet fibers were measured from microscopic pictures and then the degree of swelling was calculated from the ratio of the fiber cross sections or 


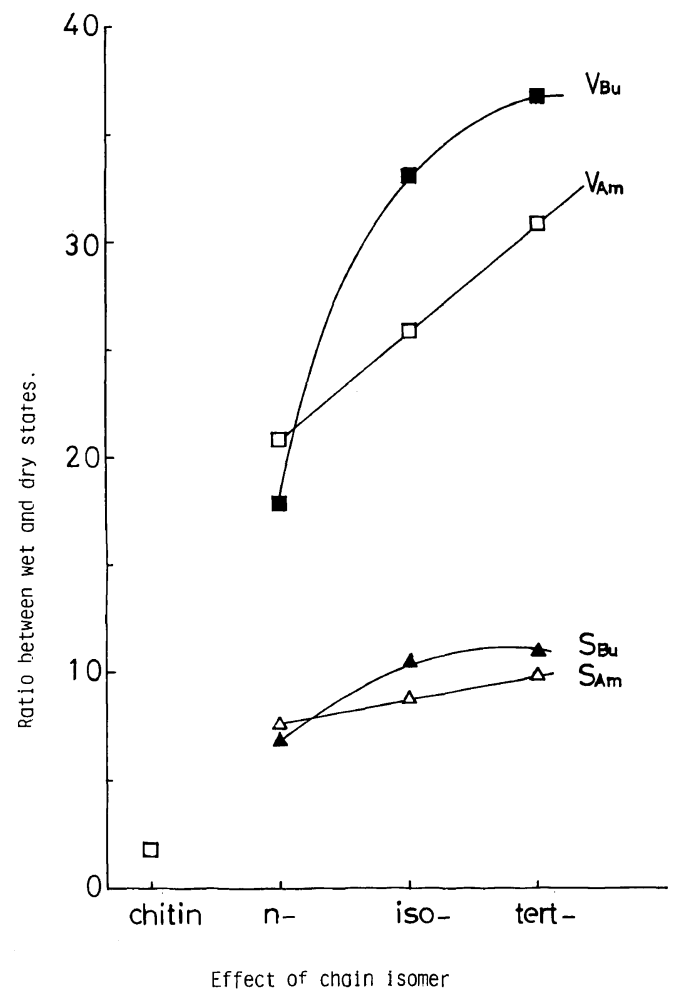

Figure 4. Dependence of degree of swelling on bulkiness of alkyl groups. $V$ and $S$ are the volume and cross section of the fibers, respectively.

volumes in the dry and wet states. The degree of swelling tended to increase with the increment in the chain length of the introduced alkyl groups as shown in Figure 3. The swelling of the fibers was also found to depend on the bulkiness of the alkyl group as shown in Figure 4. It was also noted that the complete reformation of chitin molecule might be inhibited by the presence of an alkyl group. The amount of water absorbed on alkyl-chitin fibers was measured by the Kirl-Fischer water analysis and the results are shown in Figure 5. The absorption of water depended on the bulkiness and chain length of the alkyl groups. The biregringence under the polarized light, observed for the original alkylchitin fibers, was disappeared on contact with water and a more dispersed X-ray diffraction pattern was obtained on redrying the swollen fibers. The disordered alignment of the alkyl-chitin molecule seems to take place by contact with water.

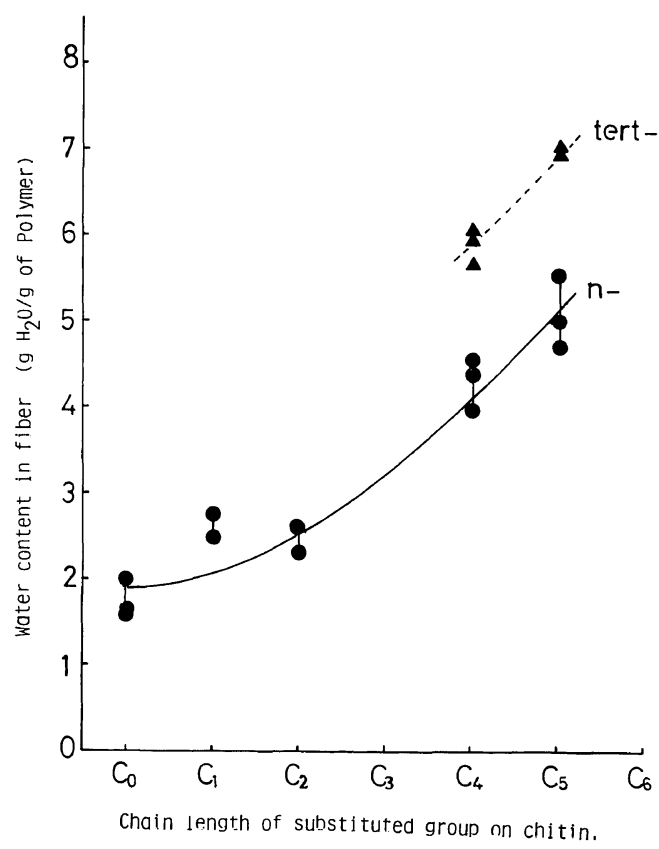

Figure 5. Dependence of fiber wettability on chain length and bulkiness of alkyl groups. Water analysis of soaked fibers was carried out using the method of KirlFischer with an automatic analyzer at $20^{\circ} \mathrm{C}$.

\section{${ }^{13} C$ and ${ }^{1} H$ NMR Studies}

The disruption of the glycoside linkage and the formylation of an $\mathrm{N}$-acetylglucosamine residue are considered to occur during the NMR mesurements, because a relatively higher temperature is required to obtain better peak separation in the deuterated formic acid. The detection of chemical shift was thus fairly difficult for samples of low degree substituion. Hence, a highly substituted chitin, 1.2 ethylated chitin solution in deuterated formic acid, was subjected to ${ }^{13} \mathrm{C}$ NMR measurement to detect the initial alkylation site on the $N$-acetylglucosamine residue. The NMR spectrum of 1.2 ethyl-chitin is shown in Figure 6 along with that of the chitin solution in deuterated formic acid. The peak area due to the ethoxy methyl group (14.7 $\mathrm{ppm})$ of 1.2 ethyl-chitin was estimated to be $10-$ $20 \%$ larger than that of acetamide group $(22.7 \mathrm{ppm})$ when both peak areas were compared with each other by the gated decoupling method. Since the degree of ethylation estimated from elemental analysis was around 1.2, the comparison of peak areas by the gated decoupling method allowed a reliable estimation of the degree of substitution on the 
Studies on Chitin. VI.

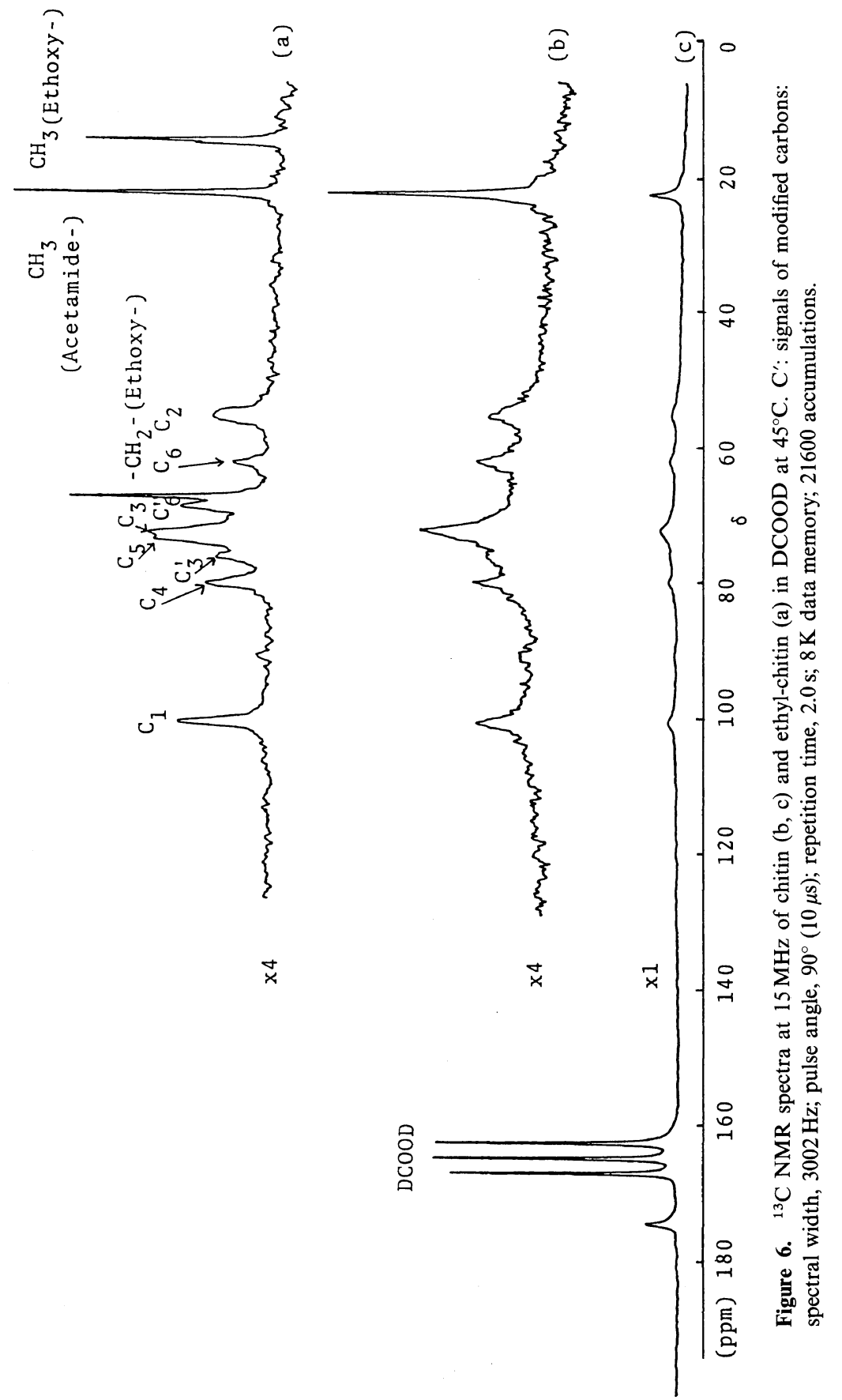


S. TOKuRA et al.

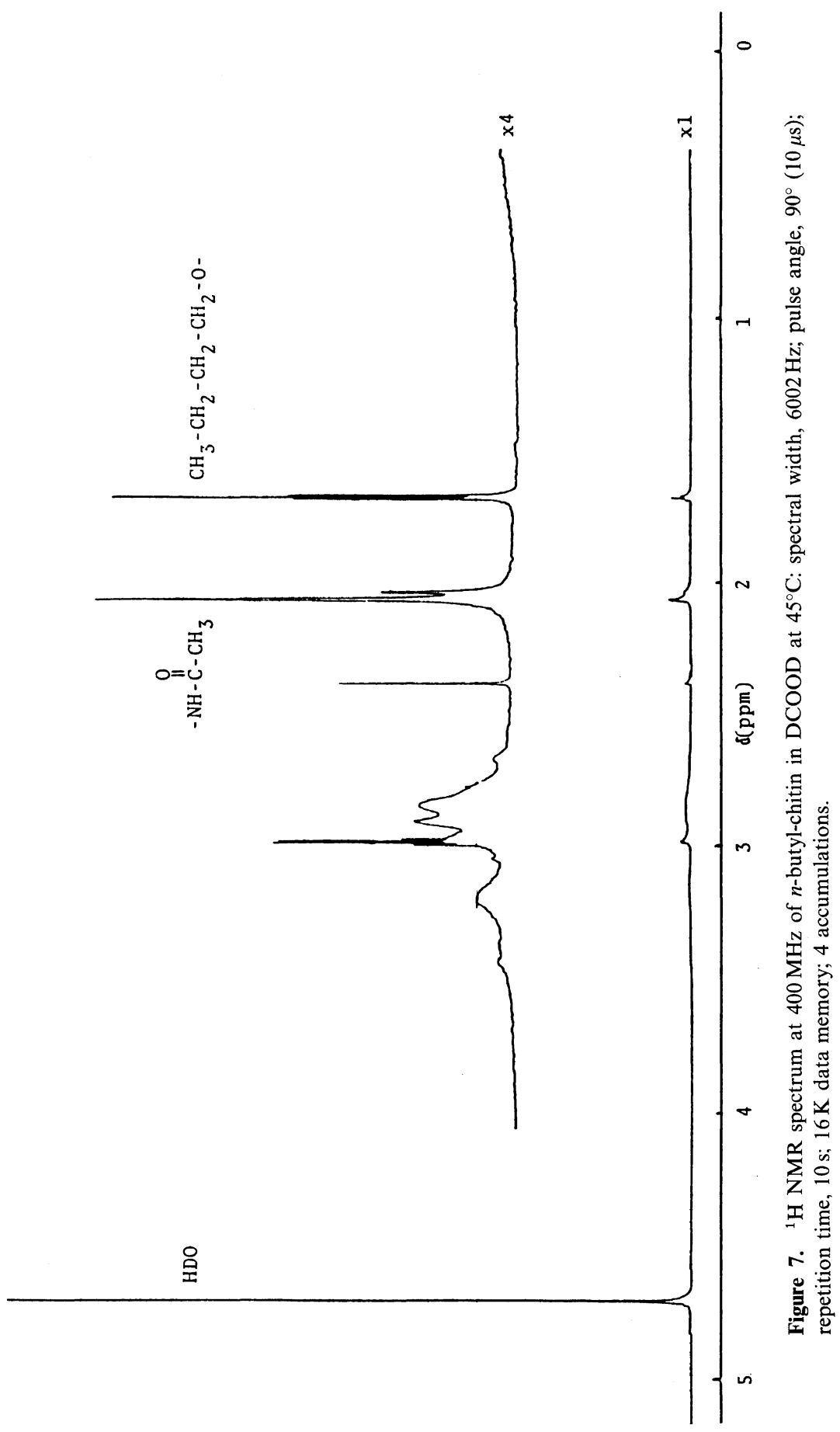


highly substituted chitin. Since the signal of the carbon attached to the hydroxyl group in the glucose is known to shift to a lower magnetic field $(8-10 \mathrm{ppm})$ when blocked with methyl group, ${ }^{14,15}$ it may be suggested that the signals at $69.4 \mathrm{ppm}$ corresponded to the ethoxylated carbon at $\mathrm{C}_{6}$ and $76.8 \mathrm{ppm}$ to that at $\mathrm{C}_{3}$ position of $\mathrm{N}$ acetylglucosamine residue. The signals of $62.6 \mathrm{ppm}$ and $74.0 \mathrm{ppm}$ are assigned to those for the unsubstituted $\mathrm{C}_{6}$ and $\mathrm{C}_{3}$, respectively, according to the ${ }^{13} \mathrm{C}$ NMR studies for glucose and the solid chitin. ${ }^{16}$ The signal at $67.7 \mathrm{ppm}$ was also assigned to the methylene of ethoxy group. The assignment for each signal is shown in Figure 6-a. The intensity ratio of the shifted signal to the unshifted one was approximately $2: 1$ for $\mathrm{C}_{6}$. The intensity ratio for $\mathrm{C}_{3}$ was approximately $1: 3.8$, although the $\mathrm{C}_{3}$ and $\mathrm{C}_{5}$ signals appeared in position very close each other, and $\mathrm{C}_{3}{ }^{\prime}$ (substituted) peak was too small for comparison. Thus $67 \%$ of hydroxyl group at $\mathrm{C}_{6}$ and $21 \%$ at $\mathrm{C}_{3}$ position were suggested to be substituted with 1.2 ethylation. There was no indication of chemical shift due to the substitued $\mathrm{C}_{3}$ on the 0.4 butyl-chitin. Therefore, the initial alkylation site may be assumed to be a primary alcohol at the $\mathrm{C}_{6}$ position. According to Pearson et al. ${ }^{9}$ two linear chain of poly- $N$-acetylglucosamine are arranged in reverse direction to form a crystalline structure of $\beta$ chitin. The rigid crystalline structure of $\beta$-chitin is contributed by the intermolecular and intramolecular hydrogen bonds. The intramolecular hydrogen bond is participated by an acetamide group at $\mathrm{C}_{2}$ and a hydroxyl group at $\mathrm{C}_{3}$ positions. The intermolecular hydrogen bond is formed between hydroxyl groups at $\mathrm{C}_{6}$ and $\mathrm{C}_{3}$ through a water molecule. The hydroxyl group at $\mathrm{C}_{3}$ position is likely covered both with intra- and intermolecular hydrogen bonds. The present work shows the substitution to be independent of the molecular shape of the alkylating reagents. The degree of alkylation was around 0.4 , indicating that a hydroxyl group at the $\mathrm{C}_{6}$ of each of the $2-3 \mathrm{~N}$-acetylglucosamine residues was substituted. On taking into account the fact that the hydroxyl group at $\mathrm{C}_{3}$ is protected by two kinds of hydrogen bonds involving water molecule, the prior alkylation of the hydroxyl group at $\mathrm{C}_{6}$ position and the low degree of alkylation on the single preparation can be reasonably explained. The loose packing of alkyl-chitin molecule may also be attributed to the disruption of the intermolecular hydrogen bond by the alkylation reaction, and along with steric hindrance, the attached alkyl group may also hinder the reformation of the rigid crystalline structure. This assumption seems to be supported by the brittle properties of wet fibers, quick swelling by soaking in water and the depression of the energy of heat transition on the alkyl-chitin fibers.

The degree of substitution was also estimated from ${ }^{1} \mathrm{H}$ NMR measurement of $n$-butyl-chitinDCOOD solution as shown in Figure 7. The area ratio of the signals of $n$-butoxy methyl group (1.67 $\mathrm{ppm})$ to acetamide methyl group (2.06 ppm) was 0.36 which is almost identical to that from elemental analysis.

Acknowledgements. The authors should like to express their appreciation to Mr. M. Ogawa of the Machine Shop of the Faculty of Science, Hokkaido University for his technical assistance and to Dr. M. Sakurai of our Department, Faculty of Science, Hokkaido University for his valuable comments. Also we are grateful to the Mitsubishi Rayon Co., Ltd. for their support.

\section{REFERENCES}

1. S. Tokura, N. Nishi, and J. Noguchi, Polym. J., 11, 781 (1978).

2. N. Nishi, J. Noguchi, S. Tokura, and H. Shiota, Polym. J., 11, 27 (1979).

3. S. Tokura, N. Nishi, O. Somorin, and J. Noguchi, Polym. J., 12, 695 (1980).

4. O. Somorin, N. Nishi, S. Tokura, and J. Noguchi, Polym. J., 11, 391 (1979).

5. K. Kaifu, N. Nishi, T. Komai, S. Tokura, and O. Somorin, Polym. J., 13, 241 (1981).

6. J. Noguchi, K. Arato, and T. Komai, Kogyo Kagaku Zasshi, 72, 796 (1969).

7. S. Tokura, N. Nishi, A. Tsutsumi, and O. Somorin, Polym. J., in preparation.

8. S. Hakomori, J. Biochem., 55, 205 (1964).

9. F. G. Pearson, R. H. Marchessault, and C. Y. Liang, J. Polym. Sci., 43, 101 (1960).

10. N. E. Dwelz, Biochem. Biophys. Acta, 51, 283 (1961).

11. P. Lepeutre, S. Hui, and A. Robertson, J. Macromol. Sci., A-10, 681 (1976).

12. J. Blackwell, R. Minke, and K. H. Gardner, Proceedings of the 1st International Conference on Chitin/Chitosan, R. A. A. Muzzarelli and E. R. Pariser, Ed., Boston, U.S.A., April, 1978, p 108.

13. C. D. Carlstrom, J. Biophys. Biochem. Cytol., 3, 669 (1957). 
S. ToKura et al.

14. D. E. Dorman and J. D. Roberts, J. Am. Chem. Soc., 92, 1355 (1970).

15. T. Usui, N. Yamanaka, K. Matsuda, K. Tsujimura, H. Sugiyama, and S. Seto, J. Chem. Soc., Perkin
Trans. 1, 2425 (1973).

16. H. Saito, R. Tabuta, and S. Hirano, Proceedings of the 1st Symposium on Chitin and Chitasan, Osaka, Japan, August, 1981, p 31. 